\title{
The Effect of Grain Size on the Susceptibility Towards Strain Age Cracking of Wrought Haynes ${ }^{\circledR} 282^{\circledR}$
}

\author{
Fabian HANNING ${ }^{\mathrm{a}, 1}$, Gurdit SINGH ${ }^{\mathrm{b}}$, Joel ANDERSSON ${ }^{\mathrm{b}}$ \\ ${ }^{a}$ Department of Industrial and Materials Science, Chalmers University of Technology, \\ Gothenburg, Sweden \\ ${ }^{\mathrm{b}}$ Department of Engineering Science, University West, Trollhättan, Sweden
}

\begin{abstract}
The effect of grain size on the suceptibility towards strain age cracking (SAC) has been investigated for Haynes ${ }^{\circledR} 282^{\circledR}$ in the tempeature range of 750 to $950^{\circ} \mathrm{C}$ after isothermal exposure up to $1800 \mathrm{~s}$. Grain growth was induced by heat treating the material at $1150^{\circ} \mathrm{C}$ for $2 \mathrm{~h}$, resulting in a fourfold increase in grain size. Hardness was significanlty reduced after heat treatment as compared to millannealed material. Large grain size resulted in intergranular fracture over a wider temperature range than small grain size material. Ductility was lowest at $850^{\circ} \mathrm{C}$, while lower values were observed to be correlated to increased grain size. The rapid formation of grain boundary carbide networks in Haynes ${ }^{\circledR} 282^{\circledR}$ is found to be not able to compensate for higher local stresses on grain boundaries due to incresed grain size.
\end{abstract}

Keywords. Welding, Nickel based superalloy, Weld cracking, Strain age cracking, Haynes ${ }^{\circledR} 282^{\circledR}$, Gleeble

\section{Introduction}

The severe environment present in the hot sections of aircraft engines requires the use of materials that can withstand high temperatures while simultaneously having high strength. Precipitation hardening nickel-based superalloys have tradidtionally been used for such appliations, with Alloy 718 being the standard grade due to its good fabricability [1]. Increasing aero engine efficiency is typically achieved by increasing combustion temperatures. This limits the applicability of Alloy 718 , which has a maximum service temperature of $650^{\circ} \mathrm{C}$. Using more temperature stable alloys such as the newly developed Haynes ${ }^{\circledR} 282^{\circledR}$ can allow a $150^{\circ} \mathrm{C}$ temperature increase [2]. The manufacturing of large structural engine components requires welding as a joining technique since small components made of both cast and wrought materials need to be joined together [3]. Haynes ${ }^{\circledR} 282^{\circledR}$ is a $\gamma^{\prime}$ hardening superalloy as opposed to Alloy 718 , which gains its high temperature strength from the $\gamma^{\prime \prime}$ phase. The former shows more rapid precipitation kinetics, which can increase the susceptibility towards strain age cracking (SAC), a weld cracking phenomenon which is characterized by intergranular cracks in the heat affected zone of welds [4]. Precipitation hardening superalloys have to be put through a post weld heat treatment (PWHT) to achieve uniform properties thorughout the whole component,

\footnotetext{
${ }^{1}$ Corresponding Author. fabian.hanning@chalmers.se
} 
which requires an age hardenend microstructure in the weld region. The fast aging kinetics of $\gamma^{\prime}$ hardening alloys can cause SAC during heating to PWHT. Precipitation reactions coincide with the relaxation of weld residual stresses. Hardening of the grain interior due to $\gamma^{\prime}$ precipitation localizes plastic deformation to grain boundaries, causing the formation of intergranular cracks. Large grain size material is generally considered to have a higher cracking susceptibility, which is explained by the localization of stresses to a lower grain boundary area [5], [6]. Haynes ${ }^{\circledR} 282^{\circledR}$ was found to show good SAC resistance [7]-[9], which was related to the materials moderate age hardening kinetics and fast formation of a complete grain boundary carbide network [9]. The latter strengthens the grain boundaries and was attributed to compensate for intragranular strength increase due to $\gamma^{\prime}$ precipitation. No information is yet available on the grain size effect on SAC in Haynes ${ }^{\circledR} 282^{\circledR}$. Considering the fast formation of grain boundary carbides in the alloy, the aim of this study is to investigate the role of grain size on the SAC susceptibility of Haynes ${ }^{\circledR} 282^{\circledR}$.

\section{Experimental}

Wrought Haynes ${ }^{\circledR} 282^{\circledR}$ in the form of $3.175 \mathrm{~mm}\left(1 / 8^{\prime \prime}\right)$ rolled sheet is investigated with the chemical composition given in Table 1 . The as-received material was used as a starting condition and as a benchmark. The material has a hardness of $265 \pm 5 \mathrm{HV}$ and a grain size of $55 \pm 5 \mu \mathrm{m}$. Primary MC-type carbides are present in the material, as shown in Figure 1, while no continuous network of grain boundary carbides is present. Some grain boundary segments are decorated with secondary carbides.

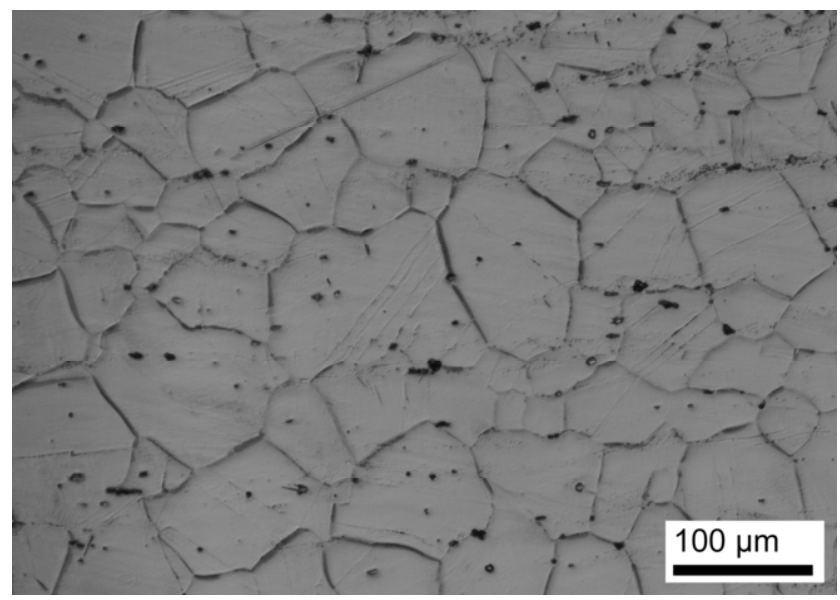

Figure 1. Microstructure in the as received with $55 \pm 5 \mu \mathrm{m}$ grain size.

Table 1. Chemical composition in wt.-\% of the Haynes ${ }^{\circledR} 282^{\circledR}$ sheet used for the experiments.

\begin{tabular}{llllllll}
\hline & Ni & Cr & Co & Mo & Fe & Mn & Al \\
wt.-\% & Bal. & 19.49 & 10.36 & 8.55 & 0.37 & 0.05 & 1.52 \\
& Ti & B & C & Cu & P & S & Si \\
wt.-\% & 2.16 & 0.005 & 0.072 & $-*$ & $-*$ & $-*$ & 0.05 \\
\hline
\end{tabular}


To investigate the effect of grain size, samples have been subjected to a heat treatment at $1150^{\circ} \mathrm{C}$, which it the upper limit of the solutionizing temperature window [10]. Samples were kept at this temperature for $2 \mathrm{~h}$ to allow for grain growth in the material, which was heat treated in the form of tensile test bars. The heat treatment has been carried out in a vacuum furnace with forced convection cooling using Ar down to $500^{\circ} \mathrm{C}$ to limit $\gamma^{\prime}$ precipitation during cooling.

A Gleeble 3800D system is used for high temperature testing on test specimens with $92 \mathrm{~mm}$ total specimen length, a $26 \mathrm{~mm}$ gauge radius and $7.5 \mathrm{~mm}$ minimum with in the gauge section. Test temperatures ranged from 750 to $950^{\circ} \mathrm{C}$ divided into $50^{\circ} \mathrm{C}$ intervals. Samples were tested using a stroke rate of $0.055 \mathrm{~mm} / \mathrm{s}$. Exposure times are shown in Table 2, together with the remaining test paramters. Tabulated exposure times include the deformation portion of the test, resulting in a maximum exposure time of $120 \mathrm{~s}$ when using a stroke rate of $0.055 \mathrm{~mm} / \mathrm{s}$.

The use of slow deformation rates was found to be necessary to produce intergranular fracture that is characteristic for SAC [9]. Three replicates were tested for each test matrix point, for which the reduction in area (RA) has been measured using an Olympus SZX9 stereo optical microscope. The test method and sample geometry is described in more detail in [9].

Table 2. Test parameters.

\begin{tabular}{|c|c|c|c|c|c|}
\hline Temperature $\left[{ }^{\circ} \mathrm{C}\right]$ & 750 & 800 & 850 & 900 & 950 \\
\hline Stroke rate $[\mathrm{mm} / \mathrm{s}]$ & & & 0.055 & & \\
\hline Exposure time $0.055 \mathrm{~m} / \mathrm{s}$ [s] & 120 & & & 1800 & \\
\hline Heating rate $\left[{ }^{\circ} \mathrm{C} / \mathrm{s}\right]$ & & & 1000 & & \\
\hline Cooling rate $\left(\mathrm{T}>500^{\circ} \mathrm{C}\right)\left[{ }^{\circ} \mathrm{C} / \mathrm{s}\right]$ & & & 100 & & \\
\hline Chamber pressure [mbar] & & & 0.1 & & \\
\hline Thermocouple & & & Type K & & \\
\hline
\end{tabular}

Specimens with a reduced geometry of $55 \times 7.5 \times 3.15 \mathrm{~mm}$ were used for microstructural investigation of undeformed material.

Microstructural characterization was carried out on cross sections of reduced-size specimens, cut out at the thermocouple location, and on fractured samples. After mounting in hot mounting resin, samples were prepared using automated grinding and polishing. $10 \mathrm{wt} .-\%$ oxalic acid at $3 \mathrm{~V}$ DC for $3-5 \mathrm{~s}$ was used to etch samples prior to microstructural characterization. A Zeiss Evo 50 scanning electron microscope (SEM) and a Leo 1550 FEG SEM have been used for the analysis.

Microhardness is measured using a Shimadzu HMV-2 microhardness tester with a force of $0.5 \mathrm{kgf}$ (HV0.5). Shown values represent the average of 5 randomly located indents. 


\section{Results and Discussion}

\subsection{Microstructural characterization}

The heat treatment at the upper limit of the solution annealing window resulted in significant grain growth, with an approximately 4-fold increase in grain size from $55 \pm$ $5 \mu \mathrm{m}$ to $205 \pm 30 \mu \mathrm{m}$. At the same time, hardness decreased to $236 \pm 2 \mathrm{HV}$. Figure 2 shows the microstructure after heat treatment at $1150^{\circ} \mathrm{C}$ for $2 \mathrm{~h}$. Apart from primary MCtype carbides, some grain boundary segments are decorated with secondary carbides. No $\gamma$ ' could be resolved on SEM images, which is not surprising considering the low hardness of the material. The presence of very fine $\gamma^{\prime}$ is however still possible. The asreceiced microstructure was found to contain $2.5 \mathrm{~nm}$ sized $\gamma^{\prime}$ precipites which were not resolvable using SEM. Their presence was instead confirmed using transmission electron microscopy [9].

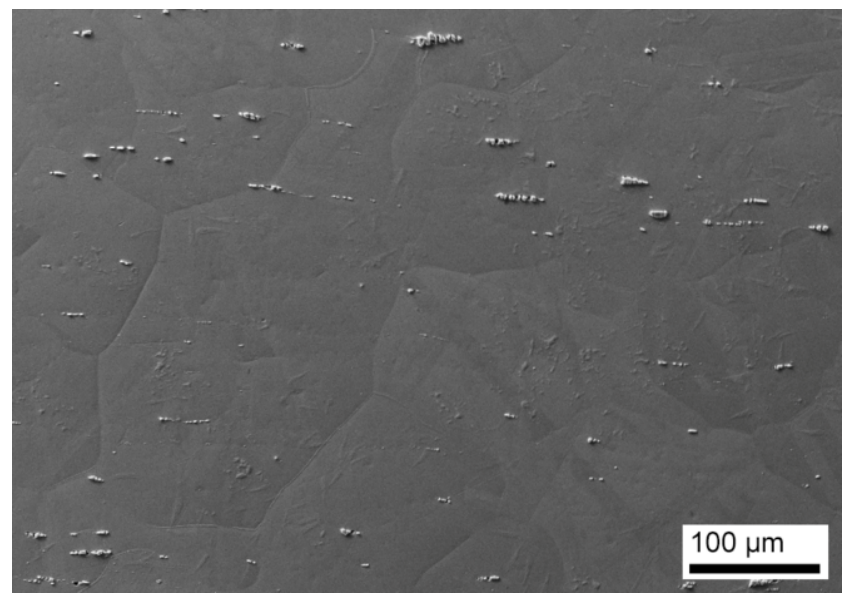

Figure 2. Microstructure after heat treatment at $1150^{\circ} \mathrm{C}$ for $2 \mathrm{~h}$, showing a significant increase in grain size.

Subsequent testing in the temperature range of $750-950^{\circ} \mathrm{C}$ did not change the grain size in both as-received and heat treated material condition. The precipitation of $\gamma^{\prime}$ can be observed for longer exposure times, which is more pronounced at the higher test temperatures. Figure 3 exemplarily shows the microstructure of samples exposed to $850^{\circ} \mathrm{C}$ for $1800 \mathrm{~s}$, where a rather similar $\gamma^{\prime}$ distribution can be observed.
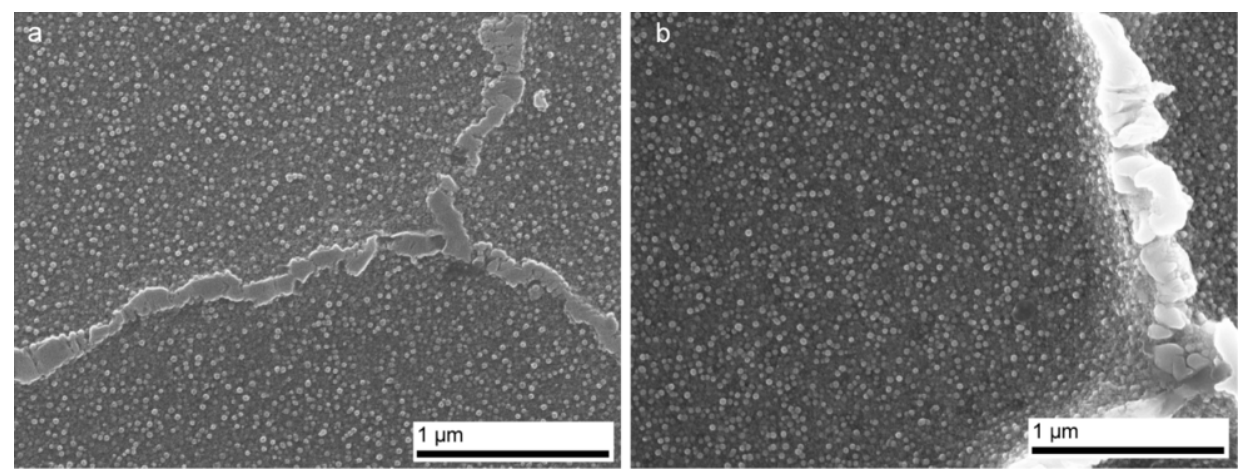

Figure 3. Comparison of $\gamma^{\prime}$ precipitation at $850^{\circ} \mathrm{C}$ after $1800 \mathrm{~s}$ ecposure time for a) small grain size and b) large grain size material. 
Furthermore, a grain boundary carbide network is developed at all test temperatures within the time window of $1800 \mathrm{~s}$. The carbide morphology is brick-like at $750^{\circ} \mathrm{C}$ and transitions towards a more discrete morphology for increased exposure temperatures, which is also found in [9]. Grain boundary carbides in Haynes ${ }^{\circledR} 282^{\circledR}$ are assumed to be of the $\mathrm{M}_{6} \mathrm{C}$ and $\mathrm{M}_{23} \mathrm{C}_{6}$ type, which are reported for the alloy in [9], [11], [12].

The $\gamma^{\prime}$ particle size has been measured on selected samples to compare the precipitation kinetics in the two material conditions. Figure 4 shows the obtained $\gamma^{\prime}$ radius as a function of temperature. While a relatively large error is present, it appears that the $\gamma^{\prime}$ particle size evolution is slightly slower after heat treatment at $1150^{\circ} \mathrm{C}$.

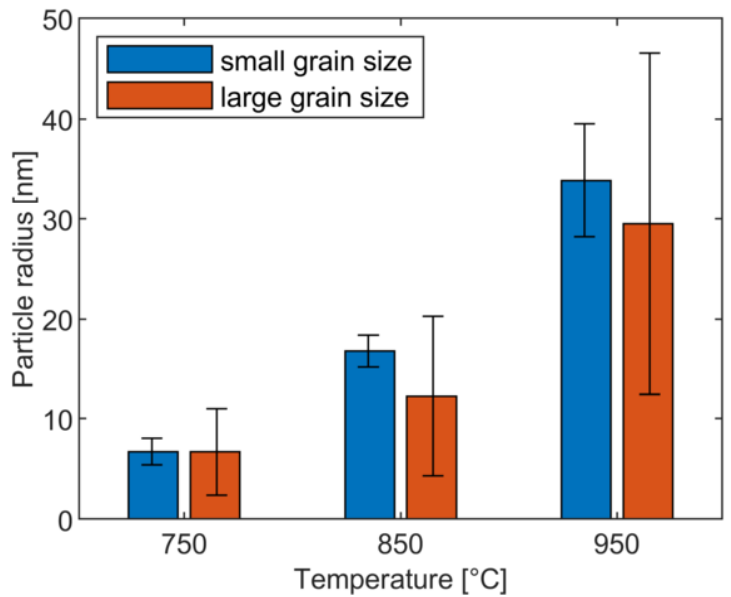

Figure 4. Measured $\gamma^{\prime}$ diameter after 1800s isothermal exposure showing a slight, but not significant difference between small and large grain size material.

Particle coarsening has been found to follow the Lifshitz-Slyozov-Wagner (LSW) theory in Haynes ${ }^{\circledR} 282^{\circledR}$ [9], [13]. The presence of $\gamma^{\prime}$ in the mill-annealed condition as reported in [9] furthermore indicate that growth is the dominating mechanism. Haas et al. found that $\gamma^{\prime}$ nucleation occurs during the first 20 minutes at $820^{\circ} \mathrm{C}$ and takes over $1 \mathrm{~h}$ to be completed at $760^{\circ} \mathrm{C}$ in Haynes ${ }^{\circledR} 282^{\circledR}$ [14], while JmatPro simuations predict the times to reach the equilibrium $\gamma^{\prime}$ phase fraction are approx. 84, 30, 13, 6 and 3.3 minutes for temperatures from 750 to $950^{\circ} \mathrm{C}$ [9]. The low hardness of $236 \pm 2 \mathrm{HV} 0.5$ after heat tratment at $1150^{\circ} \mathrm{C}$ makes it plausible that nucleation of $\gamma^{\prime}$ still occurs during the subsequent thermal exposure and hence particle growth is delayed.

Despite the similarity in $\gamma^{\prime}$ particle size, the hardness of the large grain size condition was systematically lower than that of material with small grain size. Hardness as a funciton of temperature and exposure time is shown in Figure 5 for both investigated material conditions. The highest hardness is observed at $850^{\circ} \mathrm{C}$ for both material conditions, which correlates well with the location of the precipitation nose in TTH diagrams of Haynes ${ }^{\circledR} 282^{\circledR}$ [11], [12], [14]. 

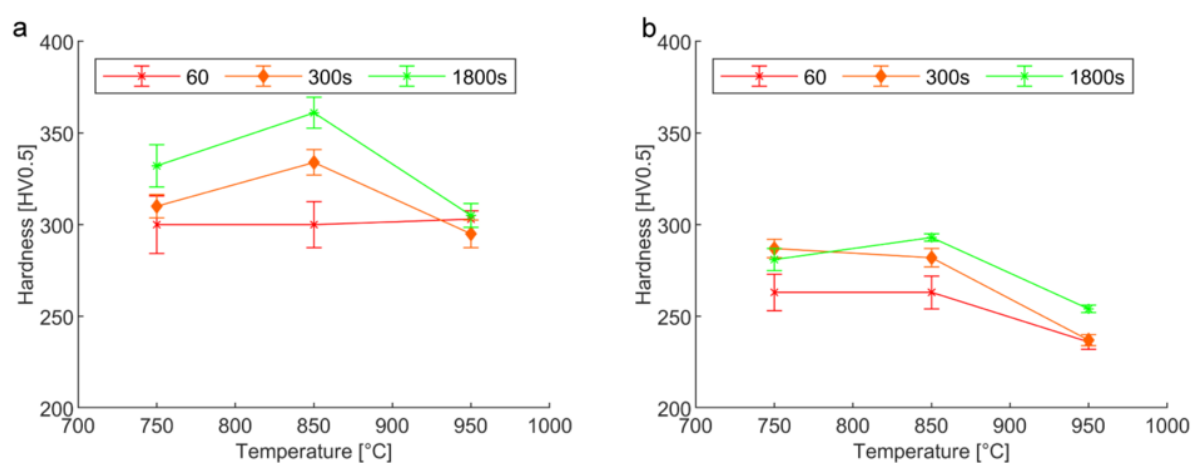

Figure 5. Hardness after isothermal exposure for a) small grain size and b) large grain size material.

The difference in hardness increase can be attributed to two contributing factors. As discussed above, the heat treatment at $1150^{\circ} \mathrm{C}$ led to a reduction in hardness as compared to the as-received condition due to the presumed faster cooling after heat treament. Hardness is however also affected by grain size. The grain size contribution to the yield strength $\sigma_{y}$ (and thereby hardness) is descibed by the Hall-Petch relationship,

$$
\sigma_{y}=\frac{\kappa}{D^{0.5}}
$$

where $\kappa$ is the Hall-petch slope and D the grain size. According to Equation 1 a fourfold increase in grain size reduces grain size contribution to the overall yield strength significantly by $50 \%$. Joseph et al. [13] used $\kappa=370 \mathrm{MPa}$ for describing the grain size contribution to the yield strength in Haynes ${ }^{\circledR} 282^{\circledR}$. Using this value for $\kappa$, the effect of the Hall-Petch contribution on the overall yield strength is however only approx. 26 and $50 \mathrm{MPa}$ for a grain size of 55 and $205 \mu \mathrm{m}$. Conversion to hardness with

$$
H V \approx 0.33 \sigma_{y}[14]
$$

shows that grain size could only account for a very small hardness difference of approx. $8 \mathrm{HV}$, making it more likely that a delayed strengthening due to $\gamma^{\prime}$ nucleation is the main cause for the difference in hardness.

Fracture surfaces are shown in Figure 6 for the investigated temperature range, where samples with small and large grain size are compared. The difference in grain size is clearly visible for samples that fractured intergranularly. It is furthermore evident that large grain size material shows intergranular fracture over a wider temperature range as samples in with the small grain size, mill-annealed, starting conditon. The latter fractures predominantly intergranularly at 800 and $850^{\circ} \mathrm{C}$ with some intergranular features being visible at 750 and $900^{\circ} \mathrm{C}$, respectively. The temperature range where fracture surfaces exhibit predominantly intergranular features ranges from 750 to $900^{\circ} \mathrm{C}$ when the grain size is large. Grain facets show micro-voids in all material conditions, indicating that plastic deformation occured on the grain boundaries. 

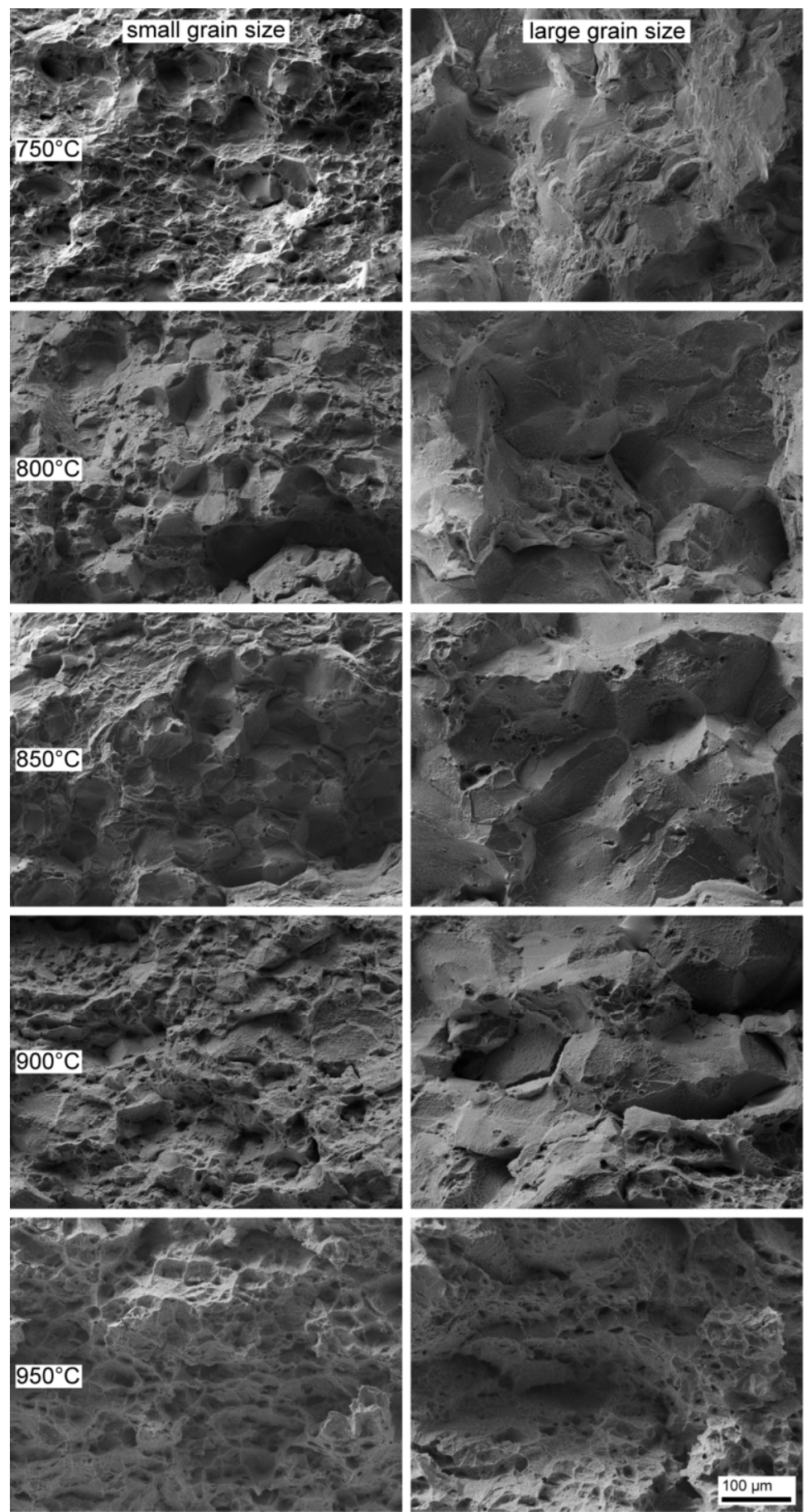

Figure 6. Fracture surfaces after 1800s isothermal exposure for samples with small and large grain size. 


\subsection{Effect of grain size on the ductility}

The ductility response during plastic deformation after isothermal exposure is shown in Figure $7 \mathrm{a}$ for small grain size, mill annealed material and $\mathrm{b}$ for the large grain size material condition.
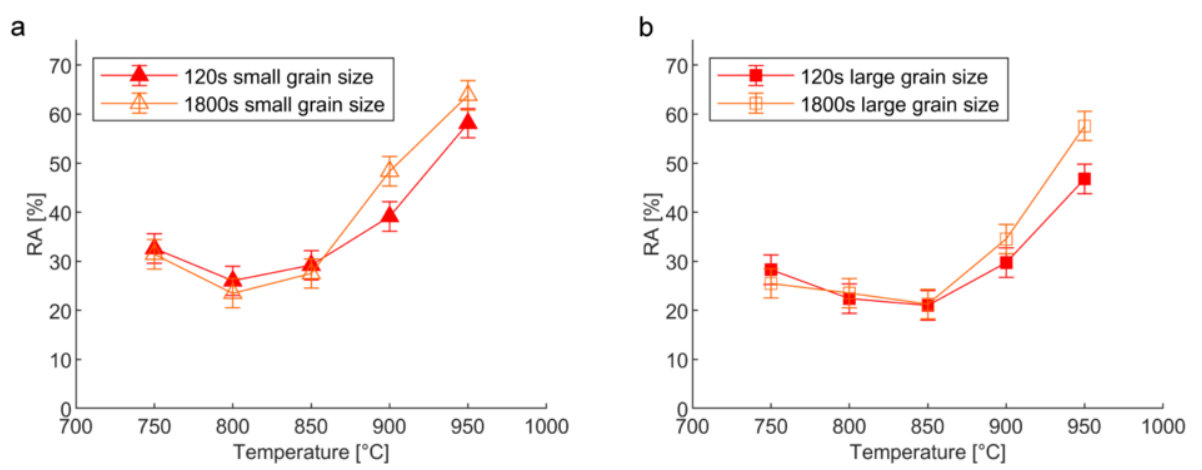

Figure 7. Ductility as a function of temperature after 120 and 1800 s isothermal exposure, with a) small grain size and b) large grain size material.

It becomes apparent that exposure time does not lead to a significant change in ductility for temperatures up to $850^{\circ} \mathrm{C}$. At higher temperatures an increase in ductility can be observed which can be attributed to thermal softening and extensive $\gamma^{\prime}$ coarsening (cf. $\gamma^{\prime}$ particle size shown in Figure 4) and a transition in grain boundary carbide morphology towards discrete particles as compared to the brick-wall structure observed at the lower temperatures. Another difference that can be observed is the relative shift of the ductility minimum from $800^{\circ} \mathrm{C}$ towards $850^{\circ} \mathrm{C}$ when grain size is increased. This goes in hand with lower absolute values ( 21 vs. $28 \% \mathrm{RA}$ at $\left.850^{\circ} \mathrm{C}\right)$. Age hardening reactions were found to not reduce the ductility in Haynes ${ }^{\circledR} 282^{\circledR}$, which has been attributed to the moderate age hardening kinetics and the rapid formation of a grain boundary carbide network in the material [9]. Hardness increase due to $\gamma^{\prime}$ precipitation was only reported to affect ductility when samples were tested with high stroke rates of $55 \mathrm{~mm} / \mathrm{s}$. This appeared to be fast enough to shift failure mode from intergranular fracture to grain rupture, where $\gamma^{\prime}$ hardening correlates with reduced ductility. For fast deformation rates, large grain size material shows a similar relationship, which makes grain size to appear having a positive effect on SAC resistance [15]. When deformation is however localized to grain boundaries, a fourfold increase in grain size leads to decreased ductility and widens the temperature range of low ductility. Assuming that a stress concentration towards grain boundaries is related to a hardness increase due to $\gamma^{\prime}$ precipitation, the systematically lower hardness of the large grain size material furthermore indicates that grain size has a large effect on ductility in Haynes ${ }^{\circledR} 282^{\circledR}$.

In practice, having low ductility in a wider temperature range increases the likeyhood of fractures occurring during heating to PWHT, rendering the large grain size material condion more susceptible to SAC. This is in good agreement with findings for other materials, where a larger grain size is connected to concentrating stresses on fewer grain boundaries and therefore leading to higher ocal stress levels in the material [5], [6]. While Haynes ${ }^{\circledR} 282^{\circledR}$ shows a generally good SAC resistance [8], [16], [17], it is an important finding that the rapid grain boundary strengthening and moderate $\gamma^{\prime}$ hardening cannot compensate for the higher local stresses present in large grain size material. It is 
hence important to control the grain size of Haynes ${ }^{\circledR} 282^{\circledR}$ when welding is used during manufacturing.

\section{Conclusions}

Haynes ${ }^{\circledR} 282^{\circledR}$ has been subjected to a solution heat treatment at $1150^{\circ} \mathrm{C}$ for $2 \mathrm{~h}$, which resulted in a fourfold increase in grain size. The ductility signature of the material has been investigated in the SAC temperature range and compared to that of mill-annealed, small grain size, material. The following can be concluded from the results:

- Significant grain growth occurs during heat treatment of Haynes ${ }^{\circledR} 282^{\circledR}$ at $1150^{\circ} \mathrm{C}$ for $2 \mathrm{~h}$

- $\quad$ The grain size contribution to the hardness of Haynes ${ }^{\circledR} 282^{\circledR}$ is low

- Lower hardness of heat treated material is related to faster cooling after heat treatment as compared to mill-annealed material

- An increase in grain size lowered the ductility in the SAC temperature range

- Low ductility in large grain size material is found over a wider temperature range

- $\quad$ Haynes ${ }^{\circledR} 282^{\circledR}$ shows increased SAC susceptibility if grain size is large $(200 \mu \mathrm{m})$

\section{Acknowledgements}

The support by the Consortium Materials Technology for Thermal Energy Processes (KME) through funding from Swedish Energy Agency and GKN Aerospace Sweden AB is highly appreciated. Johan Johansson from GKN Aerospace Swerden AB is acknowledged for carrying out the heat treatments.

\section{References}

[1] C. T. Sims, N. S. Stoloff, and W. C. Hagel, Superalloys II, Wiley, New York, 1987.

[2] L. M. Pike, HAYNES ${ }^{\circledR} 282^{\mathrm{TM}}$ Alloy - A New Wrought Superalloy Designed for Improved Creep Strength and Fabricability, In: Proceedings of ASME Turbo Expo 2006: Power for Land, Sea and Air, Barcelona, Spain, 2006, pp. 1031-1039.

[3] G. Sjöberg, Casting Superalloys For Structural Applications, In: 7th International Symposium on Superalloy 718 and Derivatives, Pittsburgh, 2010, pp. 117-130.

[4] J. C. Lippold, Welding metallurgy and weldability, John Wiley \& Sons Inc, Hoboken, New Jersey, 2015.

[5] J. B. Carlton and M. Prager, Variables Influencing the Strain-Age Cracking and Mechanical Properties of René 41 and Related Alloys, WRC Bull., vol. 150, 1970 pp. 13-23.

[6] T. F. Berry and W. P. Hughes, A Study of the Strain-Age Cracking Characteristics in Welded René 41 Phase II, Weld. J., vol. 48, no. 11, 1969 pp. 505s-513s.

[7] M. D. Rowe, Ranking the resistance of wrought superalloys to strain-age cracking, Weld. J., vol. 85, no. 2, 2006, pp. 27s-34s

[8] R. Kant and J. Dupont, Stress Relief Cracking Susceptibility in High-Temperature Alloys, Weld. J., vol. 98, no. 2, 2019 pp. 29s-49s.

[9] F. Hanning, A. K. Khan, J. Steffenburg-Nordenström, O. Ojo, and J. Andersson, Investigation of the Effect of Short Exposure in the Temperature Range of $750-950{ }^{\circ} \mathrm{C}$ on the Ductility of Haynes® $282 \AA$ by Advanced Microstructural Characterization, Metals, vol. 9, no. 12, 2019 p. 1357.

[10] Haynes International Inc., Haynes 282 Product Brochure, Publication Number H-3173, 2008.

[11] C. Joseph, Microstructure Evolution and Mechanical Properties of Haynes 282, Doctoral Thesis, Chalmers University of Technology, 2018. 
[12] M. G. Fahrmann and L. M. Pike, Experimental TTT Diagram of HAYNES 282 Alloy, In: Proceedings of the 9th International Symposium on Superalloy 718 \& Derivatives: Energy, Aerospace, and Industrial Applications, Pittsburgh, 2018, pp. 565-578.

[13] C. Joseph, C. Persson, and M. Hörnqvist Colliander, Influence of heat treatment on the microstructure and tensile properties of Ni-base superalloy Haynes 282, Mater. Sci. Eng. A, vol. 679, 2017 pp. 520-530.

[14] S. Haas, J. Andersson, M. Fisk, J.-S. Park, and U. Lienert, Correlation of precipitate evolution with Vickers hardness in Haynes ${ }^{\circledR} 282 \AA$ superalloy: In-situ high-energy SAXS/WAXS investigation, Mater. Sci. Eng. A, vol. 711, 2018, pp. 250-258.

[15] G. Singh, Effect of Grain Size on the Susceptibility towards Strain Age Cracking in the Precipitation Hardening Nickel-Based Superalloy Haynes ${ }^{\circledR} 282 \AA$, Master Thesis, University West, Trollhättan, Sweden, 2019.

[16] D. A. Metzler, A Gleeble $®$-based method for ranking the strain-age cracking susceptibility of Ni-based superalloys, Weld. J., vol. 87, no. 10, 2008, pp. 249s-256s.

[17] F. Hanning and J. Andersson, Weldability of wrought Haynes ${ }^{\circledR} 282 \circledR$ repair welded using manual gas tungsten arc welding, Weld. World, vol. 62, no. 1, 2018, pp. 39-45. 